OPEN ACCESS

Edited by:

Karen L. Reckamp, Irell \& Manella Graduate School of Biological Sciences, United States

Reviewed by:

Philipp Stroebel,

University Medical Center

Göttingen, Germany

Kazuya Kondo,

Tokushima University, Japan

${ }^{*}$ Correspondence:

Joon Seon Song

songjs@amc.seoul.kr

Se Jin Jang

jangsejin@amc.seoul.kr

†These authors have contributed equally to this work

Specialty section

This article was submitted to

Thoracic Oncology,

a section of the journal

Frontiers in Oncology

Received: 25 May 2019 Accepted: 27 September 2019 Published: 15 October 2019

Citation:

Song JS, Kim D, Kwon JH, Kim HR, Choi C-M and Jang SJ (2019) Clinicopathologic Significance and Immunogenomic Analysis of

Programmed Death-Ligand 1 (PD-L1) and Programmed Death 1 (PD-1)

Expression in Thymic Epithelial Tumors. Front. Oncol. 9:1055. doi: 10.3389/fonc.2019.01055

\section{Clinicopathologic Significance and Immunogenomic Analysis of Programmed Death-Ligand 1 (PD-L1) and Programmed Death 1 (PD-1) Expression in Thymic Epithelial Tumors}

\author{
Joon Seon Song ${ }^{1 * \dagger}$, Deokhoon Kim 1,2†, Ji Hyun Kwon ${ }^{3}$, Hyeong Ryul Kim ${ }^{4}$, \\ Chang-Min Choi ${ }^{5}$ and Se Jin Jang ${ }^{1,2 *}$
}

\begin{abstract}
${ }^{1}$ Department of Pathology, Asan Medical Center, University of Ulsan College of Medicine, Seoul, South Korea, ${ }^{2}$ Center for Cancer Genome Discovery, Asan Medical Center, Asan Institute for Life Sciences, Seoul, South Korea, ${ }^{3}$ Samkwang Medical Laboratories, Department of Pathology, Seoul, South Korea, ${ }^{4}$ Department of Thoracic and Cardiovascular Surgery, Asan Medical Center, University of Ulsan College of Medicine, Seoul, South Korea, ${ }^{5}$ Department of Pulmonology and Medical Oncology, Asan Medical Center, University of Ulsan College of Medicine, Seoul, South Korea
\end{abstract}

Objectives: Thymic epithelial tumors (TETs) are rare malignant tumors that exhibit heterogeneous histology and clinical behavior. As immune check point inhibitors, drugs targeting anti-programmed cell death protein 1 (PD-1) and programmed death-ligand 1 (PD-L1) have shown remarkable results against many cancers; thus, the importance of PD-1/PD-L1 immunohistochemistry as a predictive or prognostic biomarker has grown. However, limited data on PD-L1 and PD-1 expression in TETs have been reported; moreover, these results have been variable. Here, we examined the expression of PD-1/PD-L1 proteins in TETs and analyzed the clinicopathologic significance of this expression.

Patients and Methods: A tissue microarray was constructed using 368 samples of TETs, each in triplicate. Immunohistochemistry for PD-L1 (SP263 assay) and PD1 in TETs and CD8 in thymic carcinoma (TC) was performed; next, correlations with clinicopathologic characteristics were analyzed. PD-L1 ${ }^{\text {high }}$ was designated as $\geq 50 \%$ of tumor proportion score; $\mathrm{PD}-1^{\text {high }}$ and $\mathrm{CD} 8^{\text {high }}$ were defined as $\geq 5 \%$ and $1 \%$ of tumoral immune cells, respectively.

Results: The cohort consisted of 308 patients with thymomas and 60 patients with TC. PD-L1 positivity was identified in 90.6\% (328/362, $\geq 1 \%)$ of TETs, PD-1 expression of intra-/peritumoral T cells was identified in 53.6\% (194/362) of TETs and CD8 positivity was identified in 11\% (7/60, $\geq 1 \%)$ of TC. Of the 362 patients, 141 (39.0\%) exhibited high PD-L1 expression (PD-L1 $\left.{ }^{\text {high }}\right)$. The PD-L1 ${ }^{\text {high }}$ thymoma group was correlated with high Masaoka-Koga stage $(p<0.001)$, type B3 histology $(p<0.001)$, and myasthenia gravis $(p<0.001)$. This group exhibited poor overall survival (OS, $p=0.003$, log-rank) and worse disease-free survival (DFS, $p=0.042$, log-rank). No survival differences were detected between PD-L1 ${ }^{\text {high }}$ and PD-L1 ${ }^{\text {low }}$ groups in TC. Additionally, there was no 
correlation between PD-1 expression and survival in patients with TETs. Multivariate analysis revealed that $\mathrm{PD}-\mathrm{L} 1^{\text {high }}$ expression was an independent poor prognostic factor ( $p=0.047$, HR 2.087, 95\% Cl, 1.009-4.318) in thymomas.

Conclusions: To our knowledge, this is the largest study on TETs published in English literature. This study provides useful information regarding the prognosis of and potential therapeutic options for patients with TETs.

Keywords: thymic epithelial tumor, programmed death-1, programmed death-ligand 1, immunohistochemistry, RNA-seq

\section{INTRODUCTION}

The thymus is primarily a lymphoid organ in which $\mathrm{T}$ lymphocytes mature as a component of the adaptive immune system function. As the organ ages, it undergoes involution. After maturation, several types of mature $\mathrm{T}$ cells, including $\mathrm{CD}^{+} \mathrm{T}$ cells (helper $\mathrm{T}$ cell) and $\mathrm{CD} 8^{+} \mathrm{T}$ cells (cytotoxic $\mathrm{T}$ cells, CTLs), are fully formed. $\mathrm{CD} 8^{+}$CTLs have immune surveillance functions that aid in eliminating cancer. Thus, the number of $\mathrm{CD}^{+}$tumor-infiltrating lymphocytes (TILs) is correlated with better survival in various cancers (1-3). Programmed death-ligand 1 (PD-L1) is an immune checkpoint protein that is expressed in tumor cells. The binding of PD-L1 to its receptor, programmed cell death protein 1 (PD-1), inhibits activated $\mathrm{T}$ cell proliferation in peripheral tissues leading to "T cell exhaustion," a T cell hypo-reactive condition (4). Based on this mechanism, anti-PD-1/PD-L1 drugs have been used to treat many tumor types, including melanoma, non-small cell lung cancer (NSCLC), and head and neck cancers; the applications of these drugs have been gradually expanded to other tumor types (5-7). As these drugs are continuously used, the relevance of related biomarkers has increased. Various methods to analyze several other candidate biomarkers related to tumor immunology are under development; however, immunohistochemistry for PD-L1 is the prevalent method.

Thymic epithelial tumors (TETs), including thymoma (types $\mathrm{A}, \mathrm{AB}, \mathrm{B} 1, \mathrm{~B} 2$, and $\mathrm{B} 3$ ) and thymic carcinoma (TC), are rare malignant tumors that exhibit heterogeneous histology and clinical manifestations $(8,9)$. Surveillance, Epidemiology, and End Results (SEER) data revealed that East Asia has a higher incidence of TETs (0.25 per 100,000 person-years) than other regions (0.08-0.15 per 100,000 person-years) (8). Known strong prognostic values include the histologic subtype, Masaoka-Koga stage, and margin status (9). Complete resection is the first choice of treatment for patients with early-stage thymoma; however, chemotherapy and radiotherapy are often used locally in advanced or metastatic disease (9). Recently, a few clinical trials on anti-PD-L1 treatment for TETs with small groups of patients have been attempted, and $22.5 \%$ of patients responded favorably $(10,11)$.

Nevertheless, to date, limited data on PD-L1 expression in TETs have been reported, and these results have been variable. Here, we examined PD-L1 and PD-1 expression using clinically validated antibodies and investigated TILs in TC using CD8 immunoreactivity to evaluate their clinicopathologic significance in a large TET cohort.

\section{MATERIALS AND METHODS Patients and Specimen Collection}

We established a cohort of 368 patients with TETs who underwent surgery and neoadjuvant and/or postoperative adjuvant radiation or chemotherapy between 1996 and 2014 at Asan Medical Center, Seoul, South Korea. All cases and the related clinical data and medical records were histologically reviewed by three pathologists (JS, JK, and SJ). Pathological diagnoses and tumor subtyping were performed according to the 2015 WHO classification of TETs (9) and the Masaoka-Koga staging system (12) using the original section. When the TETs presented with mixed histologic features, they were classified according to the predominant subtype. We excluded patients from whom only biopsy specimens were obtained and patients without clinical data.

Freshly frozen tissue samples from 26 thymomas and 16 thymic carcinomas were used for molecular validation. The bio-specimens and data used in this study were provided by the Asan Bio-Resource Center of the Korea Biobank Network [Seoul, South Korea, 2015-16(106)]. This study was approved by the ethics committee of the Asan Medical Center (approval number: 2015-965).

\section{Immunohistochemistry (IHC)}

Tissue microarrays (TMAs) were constructed using 2-mm cores of representative tumor areas from paraffin-embedded blocks, in triplicate, to account for tumor heterogeneity. The sections were stained with an anti-PD-L1 (SP263) rabbit monoclonal primary antibody using the OptiView DAB IHC detection kit on a BenchMark XT automated staining platform, according to the manufacturer's instructions (13). Additional IHC for PD-1 (clone NAT 105, 1:1000, mouse monoclonal antibody, Cell Marque, Rocklin, CA, USA) in TETs and CD8 (clone C8/144B, 1:400, mouse monoclonal antibody, Cell Marque, Rocklin, CA, USA) in TC were performed using the same system. Normal tonsils were used as a positive control for PD1 and CD8. Immunohistochemistry for CD8 was performed and analyzed in only TC because normal thymic tissue also contains $\mathrm{CD} 8^{+}$immune cells, which could register as a false positive in thymomas, especially type B. 


\section{PD-L1, PD-1, and CD8 Scoring}

Three experienced pulmonary pathologists (JS, JK, and SJ) interpreted the immunoreactivity of PD-L1, PD-1, and CD8. Tumor cells were considered positive for PD-L1 expression only if membranous or membranous and cytoplasmic staining was present $(13,14)$. The percentage of positive PD-L1 expression in tumor cells (tumor proportion score, TPS) was assessed, and the average of three TPSs per case was calculated. We evaluated PD-L1 expression using a scoring system with various cut-offs (1, $5,10,25$, and $50 \%$ ) based on a previously described proportion score (Cologne score) (15), as there were no established criteria for PD-L1 in TETs. The cytoplasmic and membranous staining for PD-1 was scored according to three proportion scoring categories ( $<5 \%, 5 \sim 10 \%$ and $\geq 10 \%$ ), as previously described (16). IHC scoring of CD $8^{+}$TILS in TC was determined according to the density of cells that were positively stained for CD8; the values were classified into five proportion scoring categories $(<1$, $\geq 1, \geq 5$, and $\geq 10 \%$ ), as previously described (2).

For statistical analysis, patients were divided into high and low expression groups depending on PD-L1, PD-1, and CD8 expression. The cut-off value was more than $50 \%$ for PD-L1 (denoted as PD-L1 ${ }^{\text {high }}$ ), more than $5 \%$ for PD-1 (denoted as PD- $1^{\text {high }}$ ), and more than $1 \%$ for CD8 (denoted as CD $8^{\text {high }}$ ).

\section{Transcriptome Sequencing and Data Analysis}

Total RNA was extracted from OCT blocks using the mirVana ${ }^{\mathrm{TM}}$ miRNA Isolation Kit (Ambion), according to the manufacturer's recommended procedures. After total RNA purification, the sample was treated with DNase using a DNA-Free kit (Ambion) to eliminate potential DNA contamination that may interfere with interpretation. RNA purity was determined by assaying $1 \mu \mathrm{l}$ of the total RNA extract on a NanoDrop8000 spectrophotometer. Total RNA integrity was checked using a Bioanalyzer 2100 (Agilent Technologies, Palo Alto CA, USA) with an RNA Integrity Number (RIN) value. The quality and quantity of total
RNA was verified using a Nanodrop1000 spectrophotometer (Thermo Scientific, Wilmington, DE, USA) and a Bioanalyzer 2100 (Agilent Technologies). The sequencing library was constructed using the TruSeq RNA Access Library preparation kit (Illumina, San Diego, USA). TruSeq RNA libraries were amplified using PCR and purified. The final product was quantified using the qualitative polymerase chain reaction (qPCR), according to the qPCR Quantification Protocol Guide, and qualified using the Bioanalyzer 2100 (Agilent Technologies). Transcriptome sequencing was conducted on the HiSeq ${ }^{\mathrm{TM}} 2500$ platform (Illumina) at $2 \times 100 \mathrm{bp}$.

Sequenced reads were aligned to the human reference genome (b37) with MapSplice, and normalized expression values were calculated with rSEM (17). Unsupervised clustering was performed with the NMF package in R (18). Gene ontology (GO) was analyzed with differentially expressed genes in DAVID (19). Immune cell populations were estimated using CIBERSORT (20).

\section{Statistical Analysis}

Statistical analyses were performed using SPSS version 21.0 (Statistical Package for the Social Sciences, SPSS Inc., Chicago, IL, USA). Clinicopathologic variables of the PD-L $1{ }^{\text {high }}$ group and PD-L1 ${ }^{\text {low }}$ group were compared using $\chi^{2}$ or Fisher's exact test for nominal variables. Overall survival and disease-free survival were compared using the Kaplan-Meier method, and the survival differences were estimated by the log-rank test. Multivariate analysis using Cox regression was performed to assess clinicopathologic variables as independent factors for survival. All $p<0.05$ were considered statistically significant.

\section{RESULTS}

\section{Patient Characteristics}

Patients with thymoma $(n=308)$ and thymic carcinoma ( $n=$ 60 ) were included in the study. The most common thymoma type was type $\mathrm{AB}(n=92,29.7 \%)$, followed by type $\mathrm{B} 3(n=73,23.5 \%)$,
A

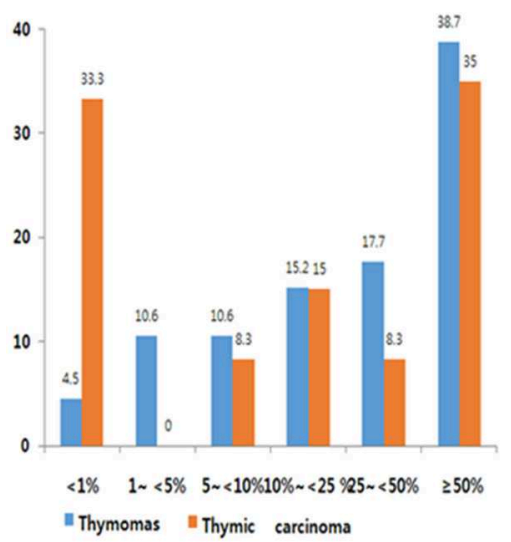

B

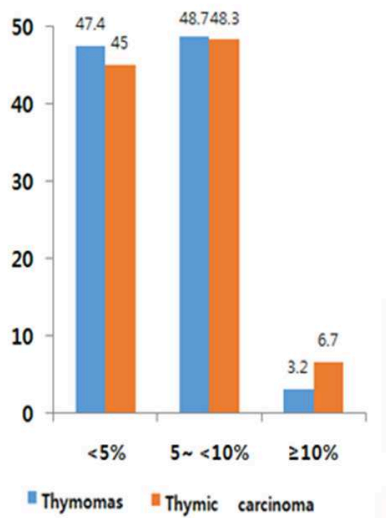

C

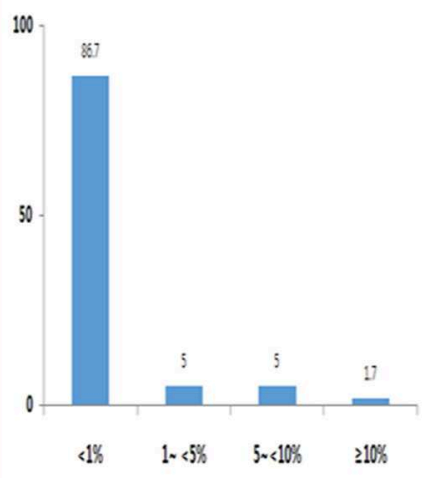

FIGURE 1 | PD-L1 (A), PD-1 (B), and CD8 (C) expression frequency. (A) Overall, 90.6\% of thymic epithelial tumors (TETs) exhibited immunopositivity for PD-L1 at cut-off of more than 1\%. High PD-L1 expression was observed in 39.0\% (cut-off over 50\%). (B) Overall, 53.6\% of TETs showed immunopositivity for PD-1. (C) Overall, $27 \%$ of thymic carcinoma samples exhibited immunopositivity for CD8. 
type B2 $(n=67,21.6 \%)$, type B1 $(n=44,14.2 \%)$, and type A $(n=32,10.3 \%)$. The median ages were 52 years (range: $15-81$ years) and 54 years (range: $28-81$ years) in the thymoma and TC groups, respectively. The male to female ratio was 1.15:1 and 1.86:1 in the thymoma and TC groups, respectively. The mean tumor size was $6.3 \mathrm{~cm}$ (range: $0.7-16.0 \mathrm{~cm}$ ) and $7.1 \mathrm{~cm}$ (range: $1.8-20.0 \mathrm{~cm}$ ) in the thymoma and TC groups, respectively. The most common Masaoka-Koga stage of the thymomas was stage I $(n=195,62.9 \%)$, followed by stage II $(n=69,22.3 \%)$, stage III $(n=37,11.9 \%)$, and stage IV $(n=7,2.2 \%)$, whereas the most common Masaoka-Koga stage of the TCs was stage III ( $n=20,33.3 \%)$, followed by stage I $(n=15,25 \%)$, stage IV ( $n=13,21.7 \%)$, and stage II $(n=12,20.0 \%)$. Myasthenia gravis (MG) was present in 73 patients (19.8\%) and all of these patients had a thymoma. The median follow-up period was 73 months (range: 2-237 months). Neoadjuvant treatment included chemotherapy (CTx) and radiation therapy (RTx). Neoadjuvant CTx included adriamycin, cisplatin, vincristine, and cyclophosphamide (ADOC, 2-6 cycles); ifosfamide and cisplatin (IP, 3-4 cycles); or etoposide and cisplatin (EP, 2 cycles). Neoadjuvant RTx was applied at 4,500 cGY in 25 fractions or $6,000 \mathrm{cGY}$ in 30 fractions. Adjuvant therapy contained CTx and RTX. Adjuvant CTx comprised 4-6 cycles of ADOC, 4 cycles of EP, or 2-6 cycles of ifosfamide, cyclophosphamide, and etoposide (ICE). Adjuvant RTx comprised 5,040 cGY in 28 fractions.

Patient data for molecular validation are summarized in Supplemental Table 1.

\section{IHC Results for PD-L1, PD-1, and CD8 Expression}

Expression frequency for PD-L1, PD-1, and CD8 is shown in Figure 1. The average TPS of PD-L1 was $39.0 \pm 31.57$ in thymoma and $33.1 \pm 35.95$ in TC. Among 302 patients with thymomas, immuno-positivity for PD-L1 was <1\%, 1-5\%, 5$10 \%, 10-25 \%$, and over $50 \%$ of TPS in $4.5 \%(14 / 302), 10.6 \%$ (33/302), $10.6 \%(33 / 302), 15.2 \%(47 / 302) 17.7 \%(55 / 368)$ and $38.7 \%$ (120/302), respectively (Figure 1A). When compared with patients with thymomas, patients with TC $(n=60)$ had a higher proportion of those with PD-L1 <1\% (33\%; Figure 1B). PD-1 frequencies in thymomas and TC were similar. Of those with TC, $86.7 \%$ patients showed immunoreactivity for CD8 at $<1 \%$, whereas only one patient $(1.7 \%, 1 / 60)$ showed immunoreactivity for CD8 at more than 10\% (Figure 1C). Representative images of IHC for PD-L1 are shown in Supplemental Figure 3.

\section{Expression Profiling of Immune Cells}

Unsupervised clustering analysis of mRNA expression profiling was performed using 42 tumor tissues, based on the 3,000 most common genes. Two groups (cluster 1 and 2) were defined. Cluster $1(n=25)$ consisted of thymomas type AB to B3 and cluster $2(n=17)$ consisted primarily of thymic carcinoma. Thus, these were correlated with the WHO classification $(p=1.021 \times$ $10^{-10}$, Fisher exact test, Figure 2A).

Gene ontology analysis revealed that differentially expressed genes between two groups were enriched for
A

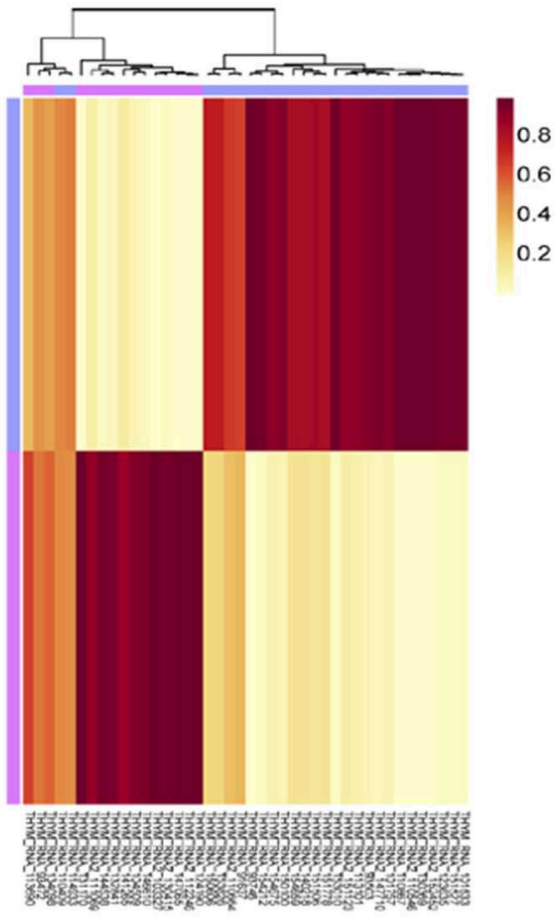

B

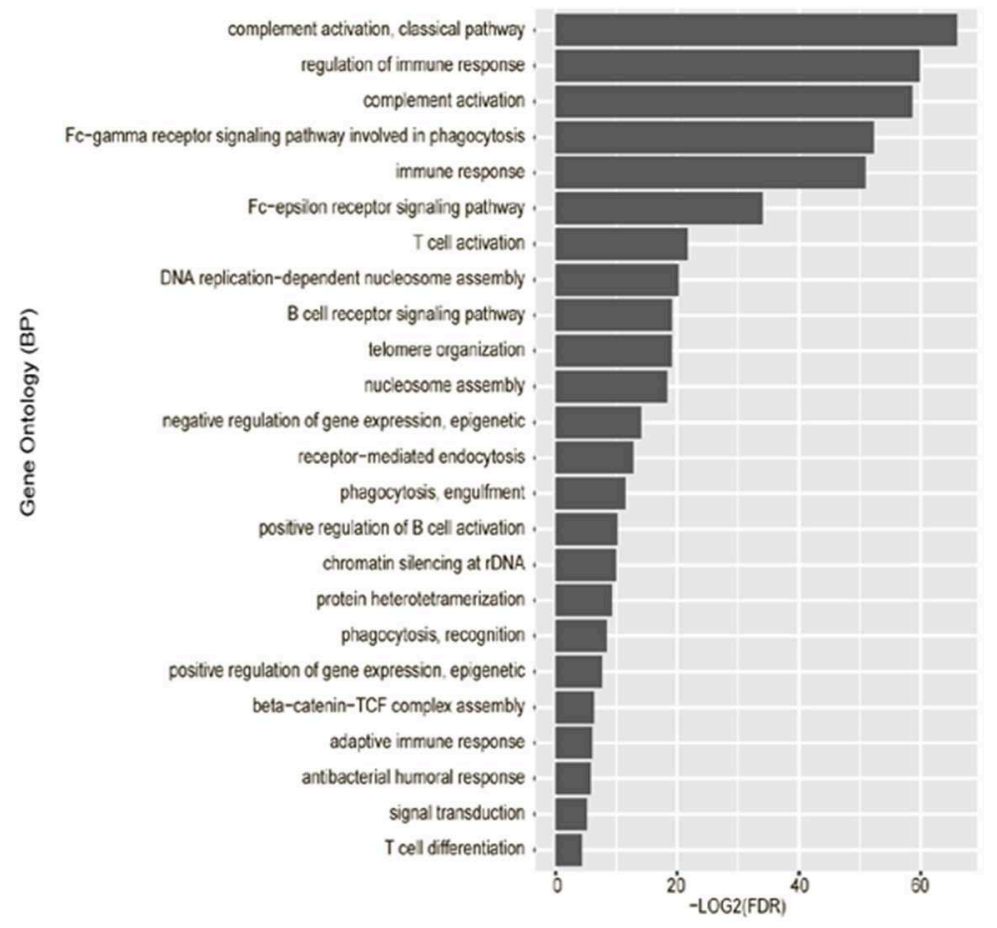

FIGURE 2 | Unsupervised clustering analysis of mRNA expression profiling. (A) mRNA expression profiling revealed characteristic clustering patterns according to thymoma types. Cluster 1 consists of thymoma and Cluster 2 consists of thymic carcinoma. (B) Immune-related terms were frequently identified in gene ontology analysis. 
A

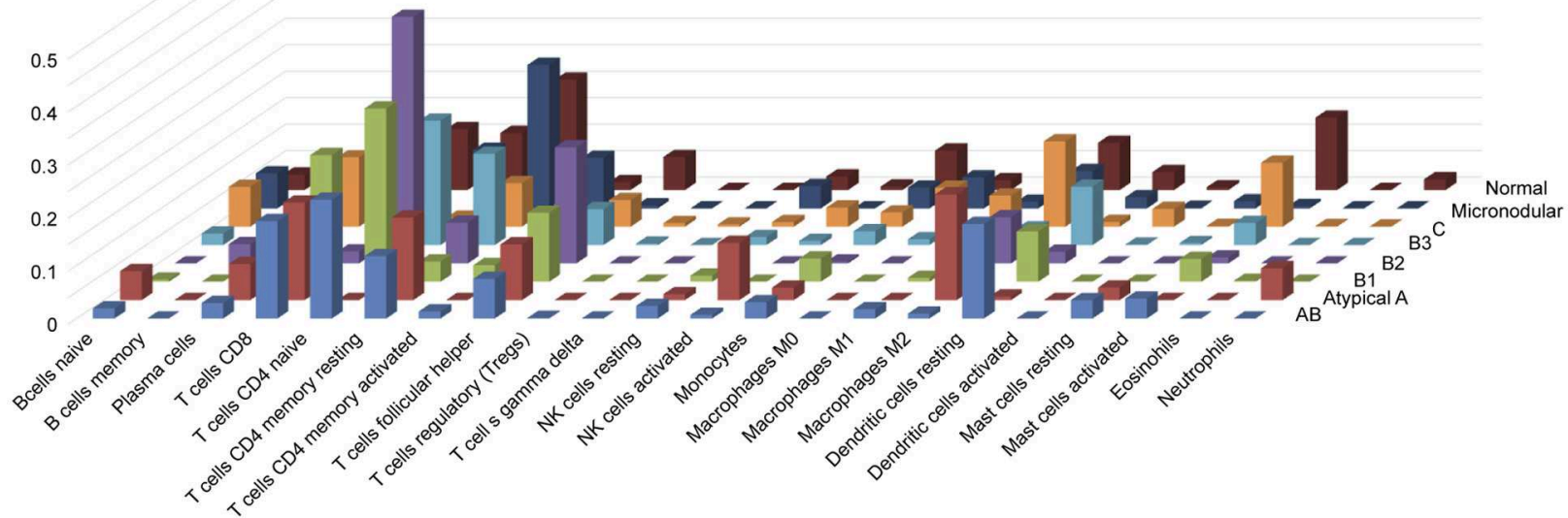

B

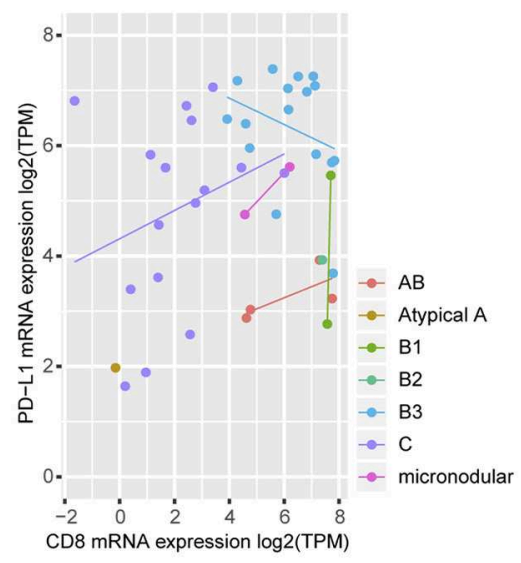

E

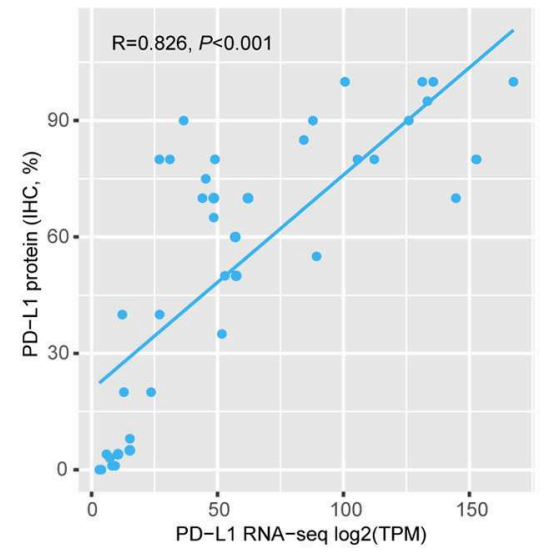

C

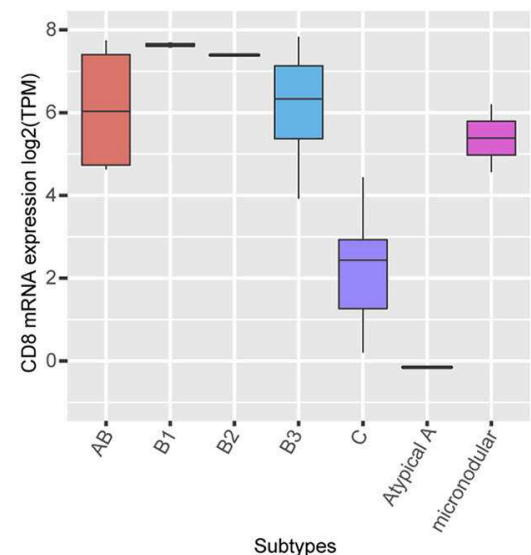

Subtypes

$\mathbf{F}$

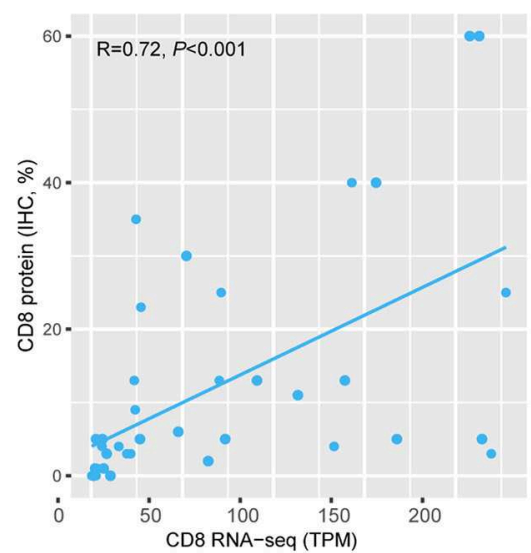

D

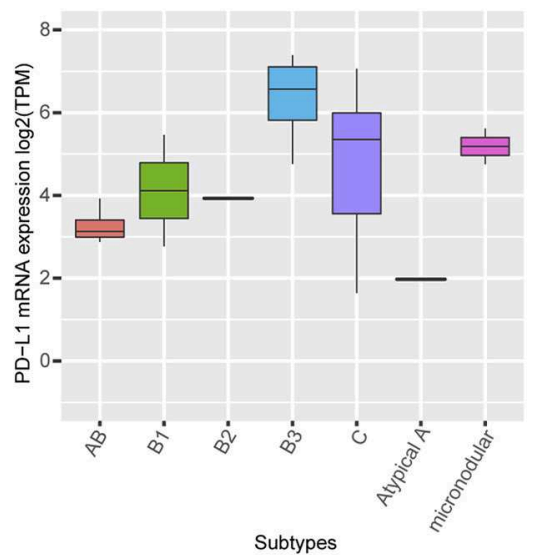

FIGURE 3 | Immune cell profiling. (A) Plasma cells and macrophages were frequently identified in the thymic carcinoma, and $\mathrm{CD} 4^{+}$and $\mathrm{CD} 8^{+} \mathrm{T}$-cells were present in the thymomas. Normal thymus tissue predominantly expressed CD4 ${ }^{+}$cells. (B) mRNA levels of CD8 and PD-L1 differed according to tumor subtype. (C) Type AB exhibited high CD8 mRNA levels. (D) Types B3 and thymic carcinoma exhibited higher PD-L1 mRNA expression than that of a normal thymus. Maximum PD-L1 expression in a normal thymus $=4.69$ transcripts per million (TPM). The cut-off value is log2 (TPM) $\geq 5$. (E,F) Both PD-L1 (e, Spearman correlation $r=0.826$, $p<0.001)$ and CD8 (f, Spearman correlation $r=0.726, p<0.001)$ protein expression correlated with mRNA level. 
TABLE 1 | Correlation between PD-L1 and PD-1 expression and clinicopathologic parameters in thymomas.

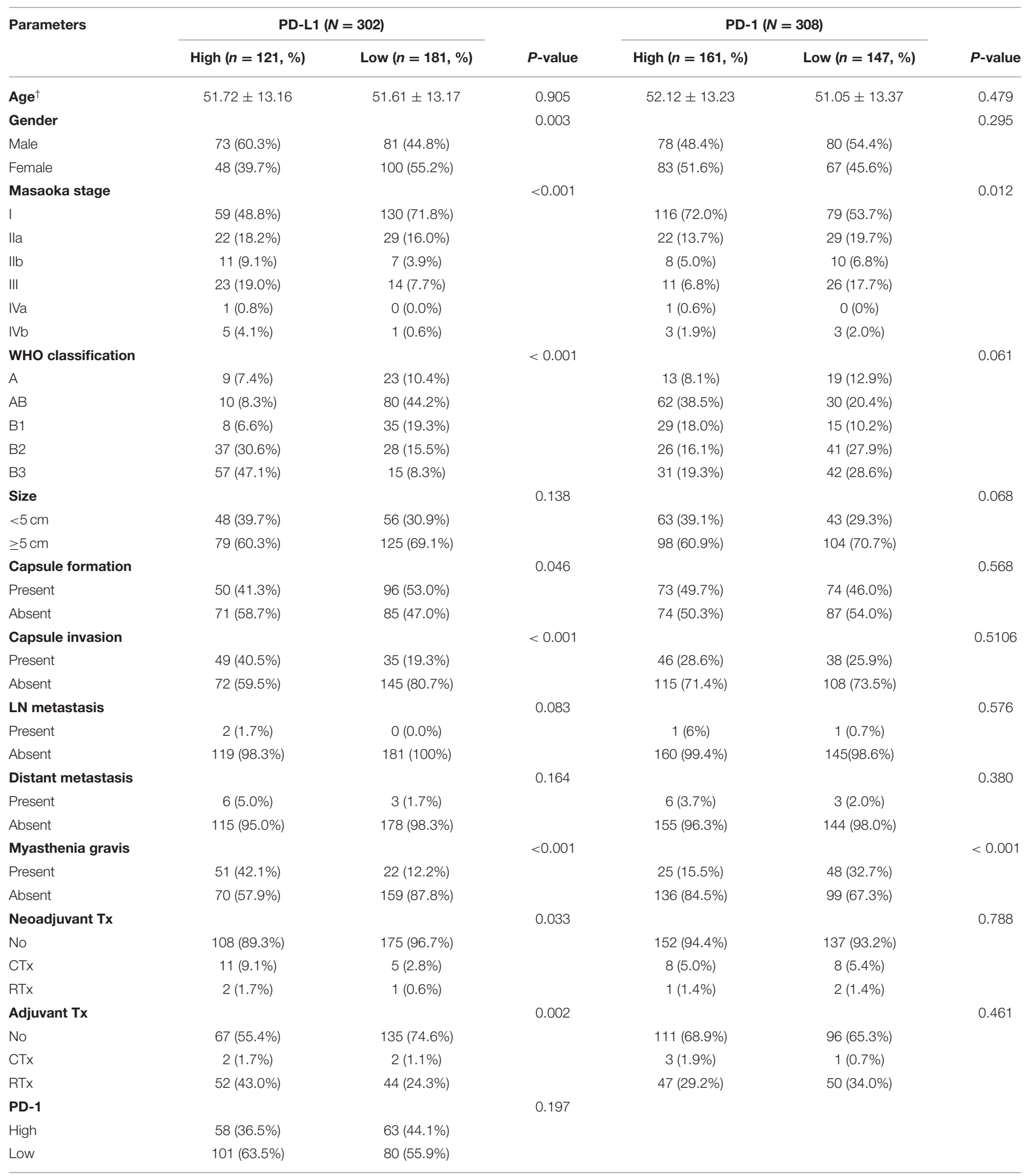

${ }^{\dagger}$ Analyzed using a t-test.

$T x$, treatment; CTx, chemotherapy; RTx, radiation therapy. 
TABLE 2 | Correlation between PD-L1 and PD-1 expression and clinicopathologic parameters in thymic carcinoma.

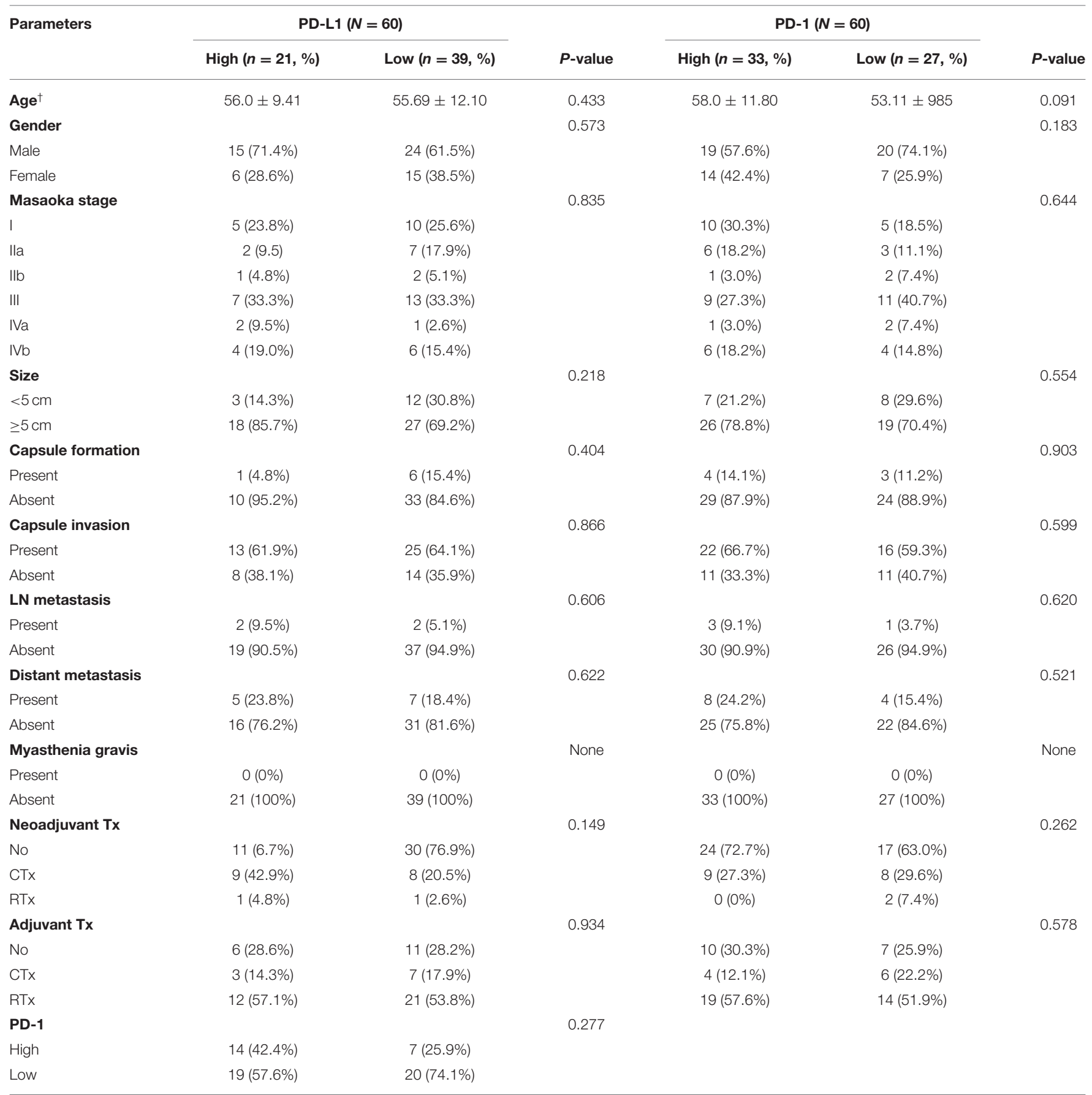

${ }^{\dagger}$ Analyzed using a t-test.

$T x$, treatment; CTx, chemotherapy; $R T x$, radiation therapy.

immune-related terms (Figure 2B). During immune cell population profiling according to tumor type, plasma cells and macrophages were more frequently observed in thymic carcinomas, whereas $\mathrm{CD}^{+}$and $\mathrm{CD}^{+} \mathrm{T}$ cells and dendritic cells were more frequently observed in the thymomas compared to the normal thymus (Figure 3A). mRNA levels of CD8 and PD-L1 differed according to tumor subtype (Figure 3B). PD-L1 and CD8 mRNA expression profiling analysis revealed that micronodular type, type B3, and thymic carcinoma were correlated with higher PD-L1 mRNA expression (Figure 3D); moreover, type A (atypical) and thymic carcinoma were correlated with lower CD8 mRNA expression (Figure 3C). Thus, patients with type B3, micronodular type, and thymic carcinoma would likely benefit from anti-PD-L1 immunotherapy based on PD-L1 mRNA expression profiling. 


\section{Correlation Between Protein Expression by IHC and mRNA Expression of PD-L1}

To evaluate the correlation between protein expression and mRNA levels, an additional TMA was constructed with paired cases for transcriptome analysis using formalin-fixed paraffinembedded tumor blocks. IHC analysis revealed that PD-L1 protein expression was positively correlated with PD-L1 mRNA expression (Spearman correlation analysis, $r=0.826, p<$ 0.001 , Figure 3E). Moreover, CD8 protein expression was also positively correlated with CD8 mRNA expression (Spearman correlation analysis, $r=0.726, p<0.001$, Figure 3F). Thus, PDL1 and CD8 IHC analysis accurately reflected the mRNA levels.

\section{Correlation Between PD-L1 and PD-1 Expression With Clinicopathologic Characteristics}

Of 308 patients with thymomas, 121 (38.7\%) were classified as PD-L1 $1^{\text {high }}$ and $181(61.3 \%)$ patients were classified as PD-L1 ${ }^{\text {low }}$. The PD-L1 ${ }^{\text {high }}$ group was correlated with male predominance ( $p$ $=0.003)$, higher Masaoka-Koga staging $(p<0.001)$, type B3 ( $p$ $<0.001)$, absence of capsule formation $(p=0.046)$, presence of capsule invasion $(p<0.001)$, presence of MG $(p<0.001)$, neoadjuvant chemotherapy group $(p=0.033)$, and adjuvant radiation therapy group $(p=0.002)$. However, other parameters, including tumor size $(p=0.138)$, lymph node metastasis $(p=$ $0.083)$, and distant metastasis $(p=0.164)$, were not correlated with PD-L1 ${ }^{\text {high }}$ classification. These results are summarized in Table 1.

Of 308 patients with thymomas, 161 (51.9\%) patients were classified as PD- ${ }^{\text {high }}$ and 147 (47.4\%) were classified as PD$1^{\text {low }}$ PD-1 $1^{\text {high }}$ was correlated with a lower Masaoka-Koga stage $(p=0.012)$ and an absence of MG $(p<0.001)$. The correlation between PD-L1 and PD-1 expression was not statistically significant $(p=0.197)$ in thymomas. These results are summarized in Table $\mathbf{1 .}$

Of 60 patients with TC, both PDL-1 and PD-1 were not correlated with any of the clinicopathologic parameters (Table 2). In addition, CD8 expression also showed the same results as PD-L1 and PD-1 (Table 3).

\section{Survival Outcomes}

The overall survival rate (OS) and disease-free survival rate (DFS) are shown in Figure 4. In thymomas, the PD-L1 ${ }^{\text {high }}$ group exhibited poorer DFS ( $p=0.042$, log-rank test, Figure 4A) and OS $\left(p=0.003\right.$, log-rank test, Figure 4B) than the PD-L1 ${ }^{\text {low }}$ group; no differences in DFS ( $p=0.444, \log$-rank test, Figure $4 \mathrm{C}$ ) and OS ( $p=0.190$, log-rank test, Figure 4D) were observed between the two groups in TC. Interestingly, the PD-L1 ${ }^{\text {high }}$ group in TC tended to exhibit good OS, although this trend was not statistically significant.

PD-1 expression was not related to survival differences in thymomas and TC (Figures 4E-H). Analysis of the PD-L1 and PD-1 expression combinations in thymomas revealed that PDL1 $1^{\text {low }} / \mathrm{PD}-1^{\text {high }}$ groups exhibited good OS $(p=0.009$, logrank, Supplemental Figure 1B) compared to PD-L1 ${ }^{\text {high }} / \mathrm{PD}-1^{\text {low }}$
TABLE 3 | Correlation between CD8 expression and clinicopathologic parameters in thymic carcinoma.

\begin{tabular}{|c|c|c|c|}
\hline \multirow[t]{2}{*}{ Parameters } & \multicolumn{2}{|c|}{ CD8 $(N=59)$} & \multirow[b]{2}{*}{$P$-value } \\
\hline & $\begin{array}{c}\text { High } \\
(n=4, \%)\end{array}$ & $\begin{array}{c}\text { Low } \\
(n=55, \%)\end{array}$ & \\
\hline $\mathrm{Age}^{t}$ & $52.8 \pm 18.30$ & $56.1 \pm 10.79$ & 0.037 \\
\hline Gender & & & 0.647 \\
\hline Male & $3(75.0 \%)$ & 35 (63.6\%) & \\
\hline Female & $1(25.0 \%)$ & $20(36.4 \%)$ & \\
\hline Masaoka stage & & & 0.780 \\
\hline I & $2(50.0 \%)$ & $13(23.6 \%)$ & \\
\hline Ila & $1(25.0)$ & $8(14.5 \%)$ & \\
\hline $\mathrm{Ilb}$ & $0(0 \%)$ & $3(5.5 \%)$ & \\
\hline III & $1(25.0 \%)$ & 19 (34.5\%) & \\
\hline IVa & $0(0 \%)$ & $2(3.6 \%)$ & \\
\hline $\mathrm{IVb}$ & $0(0 \%)$ & 10 (18.2\%) & \\
\hline Size & & & 0.248 \\
\hline$<5 \mathrm{~cm}$ & $0(0 \%)$ & $14(25.5 \%)$ & \\
\hline$\geq 5 \mathrm{~cm}$ & $4(100 \%)$ & $41(74.5 \%)$ & \\
\hline Capsule formation & & & 0.447 \\
\hline Present & $0(0 \%)$ & $7(12.7 \%)$ & \\
\hline Absent & $4(100 \%)$ & $48(87.3 \%)$ & \\
\hline Capsule invasion & & & 0.124 \\
\hline Present & 1 (25.0\%) & 37 (67.3\%) & \\
\hline Absent & $3(75.0 \%)$ & $18(32.7 \%)$ & \\
\hline LN metastasis & & & 0.576 \\
\hline Present & $0(0 \%)$ & $4(7.3 \%)$ & \\
\hline Absent & $4(100 \%)$ & $51(92.7 \%)$ & \\
\hline Distant metastasis & & & 0.290 \\
\hline Present & $0(0 \%)$ & $12(22.2 \%)$ & \\
\hline Absent & $4(100 \%)$ & $42(77.8 \%)$ & \\
\hline Myasthenia gravis & & & None \\
\hline Present & $0(0 \%)$ & $0(0 \%)$ & \\
\hline absent & $4(100 \%)$ & 55 (100\%) & \\
\hline Neoadjuvant Tx & & & 0.546 \\
\hline No & 2 (50.0\%) & 39 (70.9\%) & \\
\hline CTx & $2(50.0 \%)$ & 14 (25.5\%) & \\
\hline RTx & $0(0 \%)$ & $2(3.6 \%)$ & \\
\hline Adjuvant Tx & & & 0.580 \\
\hline No & $1(25.0 \%)$ & $16(29.1 \%)$ & \\
\hline CTx & $0(0 \%)$ & 10 (18.2\%) & \\
\hline RTx & $3(75.0 \%)$ & $29(52.7 \%)$ & \\
\hline PD-L1 & & & 0.481 \\
\hline High & $2(50.0 \%)$ & $18(32.7 \%)$ & \\
\hline Low & 2 (50.0\%) & 37 (67.3\%) & \\
\hline
\end{tabular}

${ }^{\dagger}$ Analyzed using a t-test.

$T x$, treatment; CTx, chemotherapy; $R T x$, radiation therapy.

group; however, no differences in DFS were observed ( $p=0.082$, log-rank, Supplemental Figure 1A).

The CD $8^{\text {high }}$ group in TC tended to exhibit good OS, but the results were not statistically significant for OS $(p=0.351$, $\log$-rank, Figure 5A) and DFS ( $p=0.913, \log$-rank, Figure 5B). 

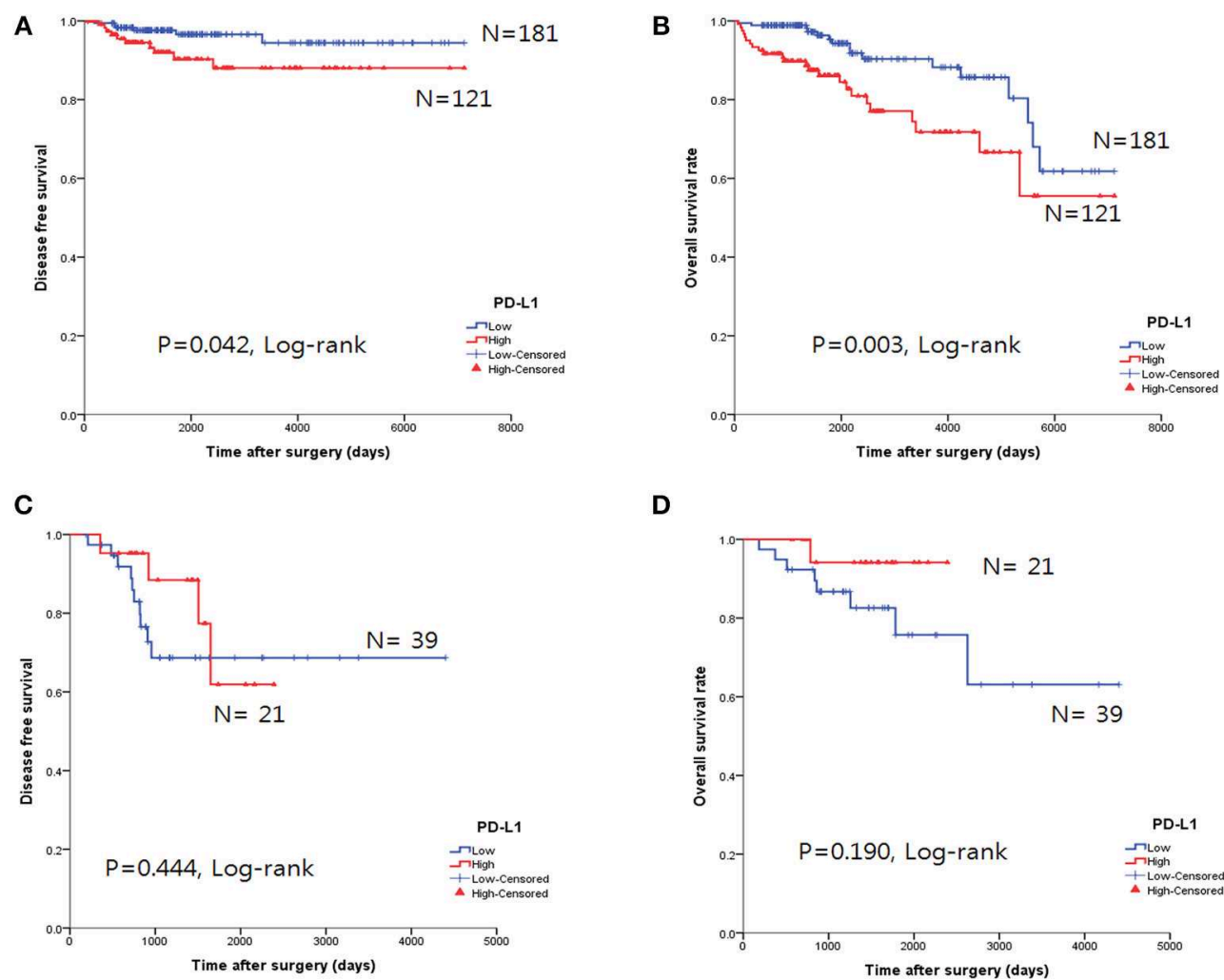

D

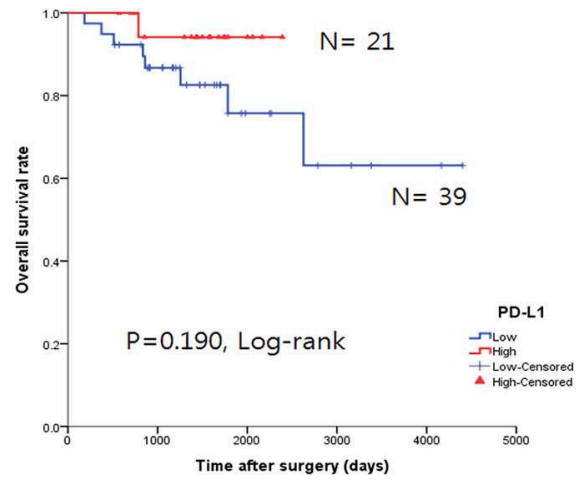

E

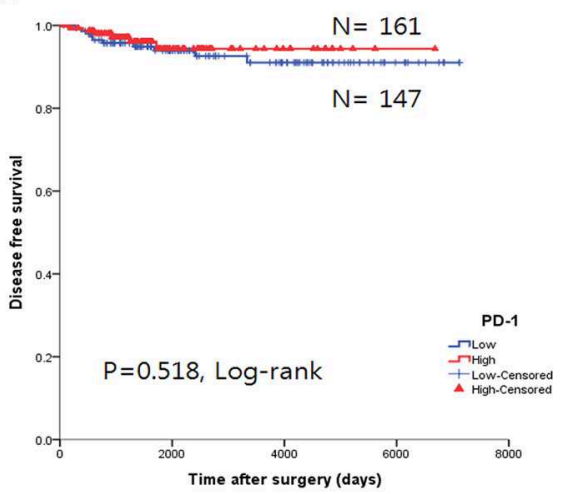

$\mathbf{F}$
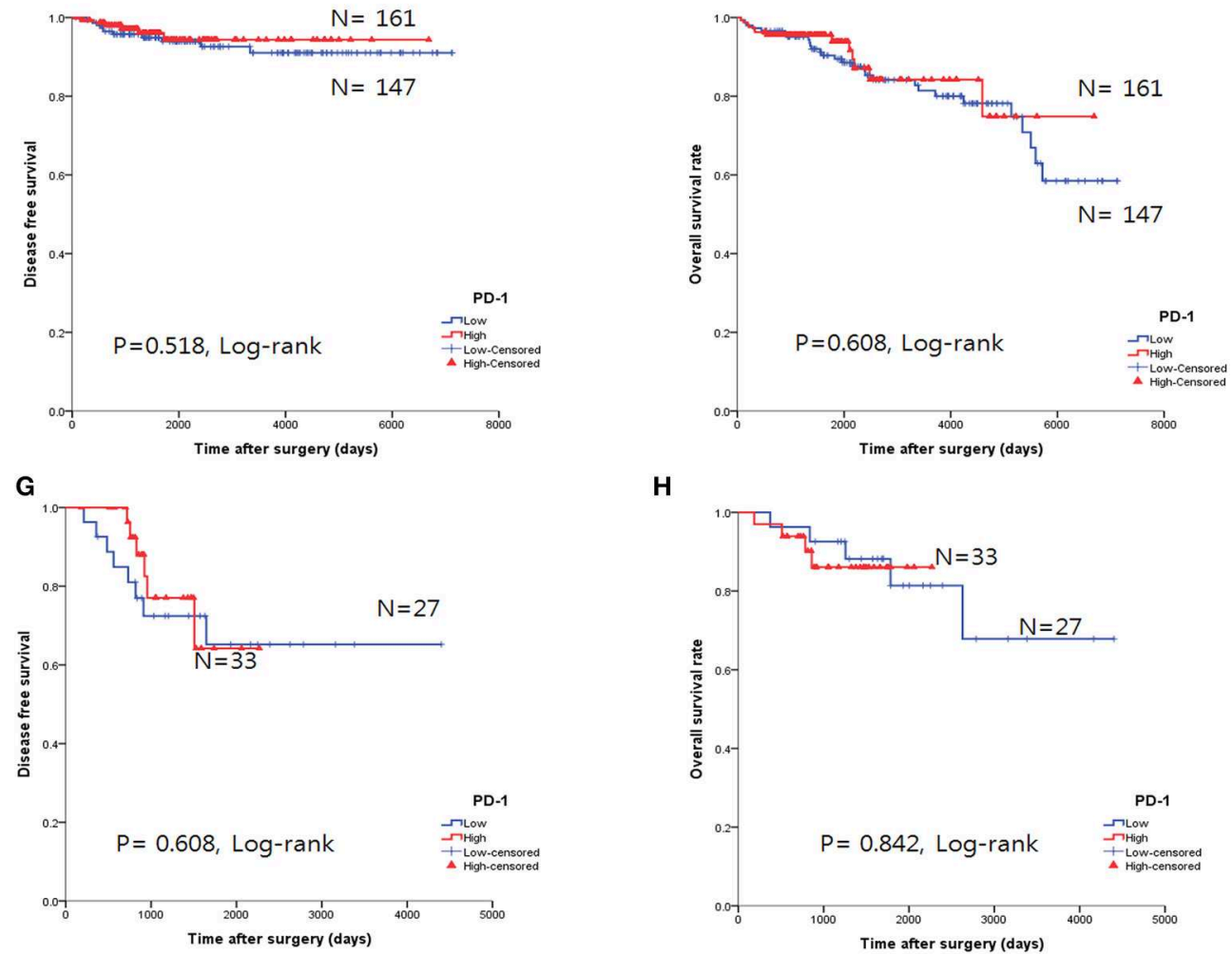

FIGURE 4 | Survival analysis using the Kaplan-Meier method according to PD-L1 and PD-1 expression. (A,B) The PD-L1 high group correlated with poor overall survival (OS, B) and disease-free survival (DFS, A) in thymomas. (C,D) No survival differences, according to PD-L1 expression, were observed in thymic carcinoma. $\mathbf{( E - H ) ~ N o ~ s u r v i v a l ~ d i f f e r e n c e s ~ i n ~ t h e ~ s t a t u s ~ o f ~ P D - l ~ e x p r e s s i o n ~ w e r e ~ i d e n t i f i e d ~ i n ~ e i t h e r ~ t h y m o m a s ~ ( E , F ) ~ o r ~ t h y m i c ~ c a r c i n o m a ~ ( G , H ) . ~}$ 

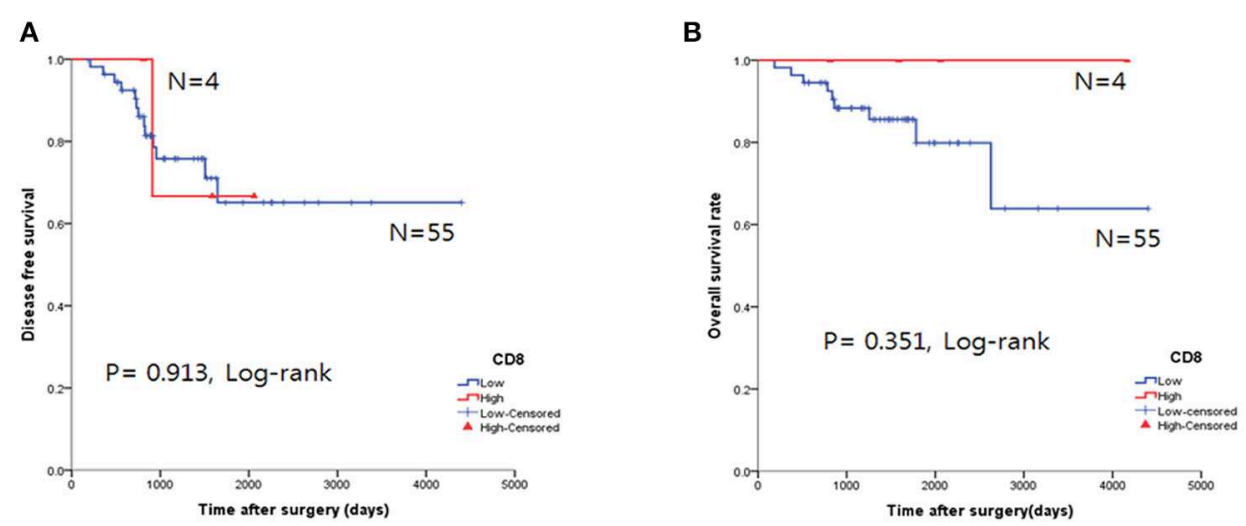

C

D
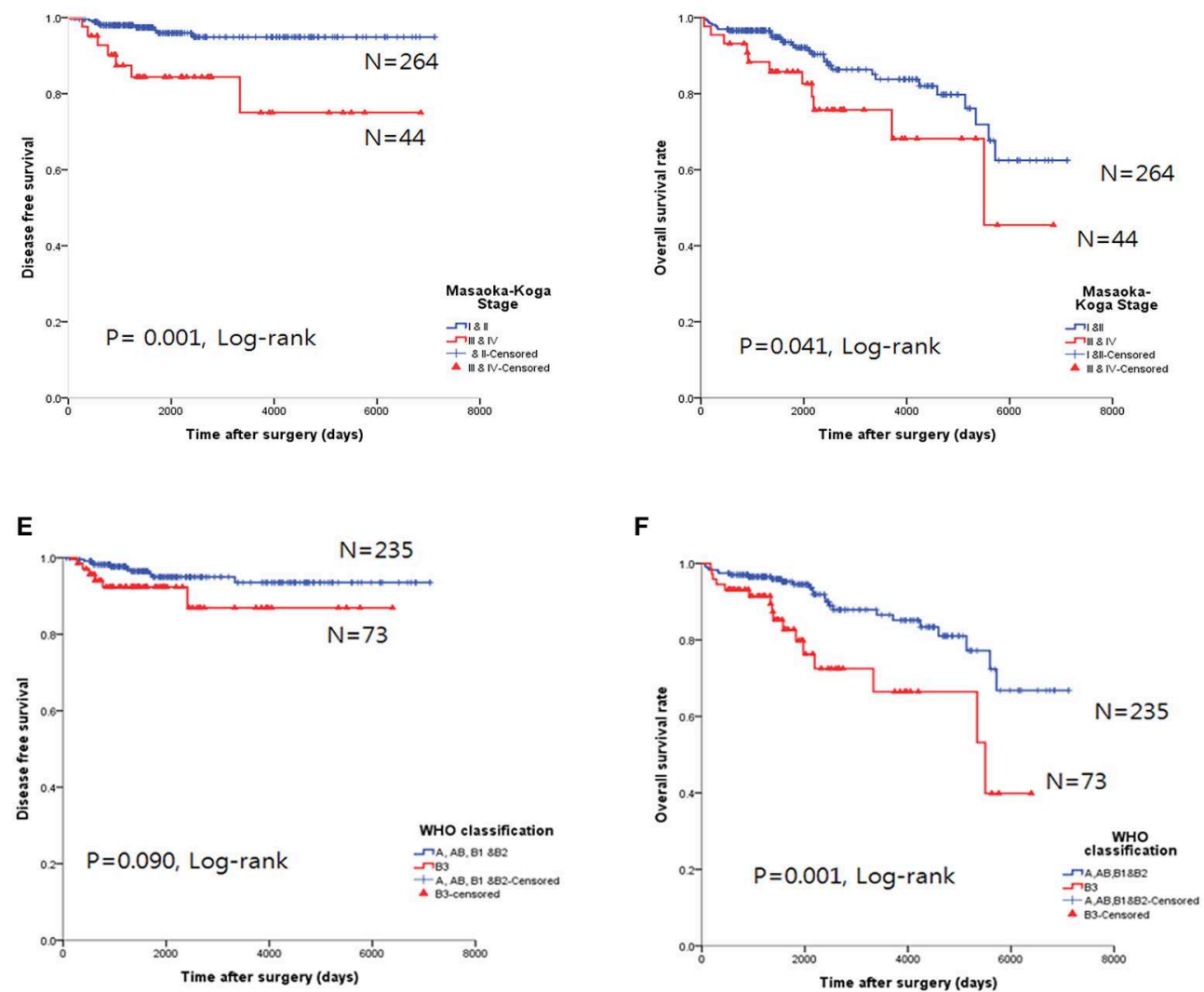

FIGURE 5 | Survival analysis using the Kaplan-Meier method. (A,B) The CD $8^{\text {high }}$ group was not correlated with either overall survival (OS, A) or disease-free survival (DFS, B) in thymic carcinoma. (C,D) Higher Masaoka-Koga stage in thymoma was correlated with both poor OS and DFS. (E,F) Type B3 was correlated with poor OS in thymomas; however, DFS was not significant.

Higher Masaoka-Koga stages $(p=0.041$, log-rank test, Figure 5D) and type B3 group ( $p=0.001$, log-rank, Figure 5F) in thymomas presented poor OS prognosis. In the univariate analysis, Masaoka-Koga stage $(p=0.041)$, WHO classification $(p=0.001), \mathrm{PD}-\mathrm{L} 1^{\text {high }}(p=0.003)$, neoadjuvant treatment $(p$ $=0.002)$, and adjuvant treatment $(p<0.001)$ were statistically significant (data not shown). However, in the multivariate analysis, $\mathrm{PD}-\mathrm{L} 1^{\text {high }}$ was an independent poor prognostic factor for OS ( $p=0.047, \mathrm{HR} 2.09,95 \% \mathrm{CI}, 1.009-4.318)$ of thymomas. These findings are shown in Table 4.

\section{DISCUSSION}

We evaluated PD-L1, PD-1, and CD8 expression in patients with thymomas and TC in the largest cohort study to date and analyzed the clinicopathological significance of this expression. 
TABLE 4 | Multivariate analysis for overall survival in thymomas.

\begin{tabular}{|c|c|c|c|c|}
\hline Parameter & & $P$-value & HR & $95 \% \mathrm{Cl}$ \\
\hline Masaoka-Koga stage & {$[\mathrm{I}, \mathrm{II}]$ vs. III, IV } & 0.617 & 1.266 & $0.503-3.186$ \\
\hline WHO classification & {$[A, A B, B 1, B 2]$ vs. B3 } & 0.065 & 2.063 & $0.956-4.449$ \\
\hline \multirow[t]{2}{*}{ Neoadjuvant Tx } & [none] vs. CTx & 0.507 & 0.599 & $0.132-2.719$ \\
\hline & [None] vs. RTx & 0.151 & 3.382 & $0.642-17.832$ \\
\hline \multirow[t]{2}{*}{ Adjuvant Tx } & [None] vs. CTx & 0.003 & 9.763 & $2.189-43.552$ \\
\hline & [None] vs. RTx & 0.086 & 0.477 & $0.205-1.110$ \\
\hline PD-L1 & [Low] vs. high & 0.047 & 2.087 & $1.009-4.318$ \\
\hline
\end{tabular}

[] represents the reference parameters. HR represents hazard ratio. Cl represents confidence interval.

$T x$, treatment; CTx, chemotherapy; $R T x$, radiation therapy.

We reviewed published studies on PubMed related to PD-L1 expression in TETs and summarized them in Table 5. Briefly, 18 studies were published in English, and the subjects examined in these studies ranged from 12 to 101 patients for thymoma and 3 to 69 patients for thymic carcinoma. The most frequent antibody evaluated was E1L3N $(n=6)$, followed by SP142 $(n=5), 22 \mathrm{C} 3$ $(n=1)$, and SP263 $(n=1)$. The interpretation criteria for PD-L1 in TETs have not yet been determined, and variable criteria were used according to the proportion of positive cells, intensity, or both. PD-L1 expression ranged from 18 to $92 \%$ in thymoma and 36.2 to $100 \%$ in TC. High PD-L1 expression was correlated with higher Masaoka-Koga staging in six studies (21, 22, 27, 32, 34, 36) and associated with WHO classification of type B and/or thymic carcinoma in eight publications (22, 23, 27, 31, 32, 34-36). Most studies did not report differences in OS between the high and low PD-L1 expression groups $(n=11)(16,22,24-27,29,30,32$, $33,35)$, and three studies reported worse OS in the high PD-L1 expression group $(21,36,37)$. In contrast, two studies reported better OS in the high PD-L1 expression group $(24,28)$.

Immunopositivity for $\mathrm{PD}-1$ in thymoma ranged from 44 to $81 \%$ in thymomas and 23 to $47 \%$ in $\mathrm{TC}(16,25,26,29)$, indicating a trend of much lower expression of PD-1 in TC than in thymomas. However, our study identified similar frequencies of PD-1 expression between thymomas (51.9\%) and TC (55.0\%). Moreover, Katsuya et al. (25) showed similar PD-1 expression in TC and thymomas ( $47 \%$ vs. $44 \%$ ). No survival benefit in the PD-1 high expression group was observed in thymomas or TC in some studies $(16,25,26,29)$; our results were also similar. Weissferdt et al. (16) showed that PD-1 positive cases were associated with higher stage in TC; however, most studies revealed that PD-1 positivity was not associated with any parameters in thymomas or TC $(25,26,29)$. We found that high PD-1 expression was correlated with lower Masaoka-Koga stage $(p=0.012)$ and absence of MG $(p<0.001)$ in thymoma, but, as in previous studies, no correlations with parameters were observed in TC.

Recently, the US Food and Drug Administration (FDA) approved the use of four anti-PD-1/PD-L1 drugs, including pembrolizumab, nivolumab, atezolizumab, and durvalumab, for the treatment of NSCLC, according to different corresponding immunohistochemical assays as companion or complementary diagnostic tests. In other words, each assay has a specific cutoff value for positive tumor cells, and the percentage may differ depending on whether the treatment was the first chosen treatment, even for the same drug in NSCLC. In addition, when an assay, such as SP263, is applied for two drug prescriptions, different cutoffs may be applied, depending on the drug. In Korea, the SP263 assay uses two different cut-offs for NSCLC: $25 \%$ for durvalumab (38) and $10 \%$ for nivolumab. These inconsistent cutoffs are not proven by clinical trials, except for durvalumab (38). However, a special situation that coincides with the national insurance policy in Korea causes pathologists to focus on insurance policies related with PD-L1 treatment. Several studies have shown that high PD-L1 expression is correlated with a better response to anti-PD-L1 therapy in $\operatorname{NSCLC}(7,39,40)$. In TETs, it may be expected that high PD-L1 expression would lead to a better response to anti-PD-L1 treatment, such as in NSCLC; however, the limited clinical trials of anti-PD-L1 therapy in TETs $(10,11)$ have shown controversial results. In a previous study, Giaccone et al. (10), using the 22C3 antibody for PDL1, with a cutoff of more than $50 \%$, revealed a better response in the high PD-L1 expression group, whereas Kim et al. (11) reported no significant response difference according to PD-L1 expression, with the same antibody and cutoff. Thus, the role of $\mathrm{PD}-\mathrm{L} 1$ expression in TETs as a predictive marker for anti-PD-L1 treatment is still somewhat unknown.

As the cutoff of SP263 is not yet proven by clinical trials in TETs, we determined the cut-off as $50 \%$ because it is more highly expressed in TETs than in NSCLC. We found that the average TPS of 753 patients with NSCLC for SP263 was $25.02 \pm$ 33.14 (data not shown), whereas it was $38.06 \pm 32.35$ in TETs. In addition, clinicopathologic correlations were more highly reflected at a cutoff of 50\% than 25\% (Supplemental Table 2, Supplemental Figure 2). The results obtained with the $25 \%$ cutoff were very similar to those of Guleria et al.; WHO classification of type B was correlated with PD-L1 high (31). Thus, an accurate pathologic diagnosis is crucial.

Several studies have reported the interchangeability of antiPD-L1 antibodies in NSCLC; moreover, it has been reported that positive rates for PD-L1 were similar with high concordance under assay-specific cutoffs, except for SP142 (15, 41-43). Additionally, Sakane et al. (44) conducted a comparative study of PD-L1 immunohistochemical assays in thymic carcinoma, revealing results similar to those in NSCLC. Previous studies primarily used E1L3N clones in TETs $(16,22,25,27,28,32)$. 
TABLE 5 | Summary of published series of PD-L1 expression in thymic epithelial tumors.

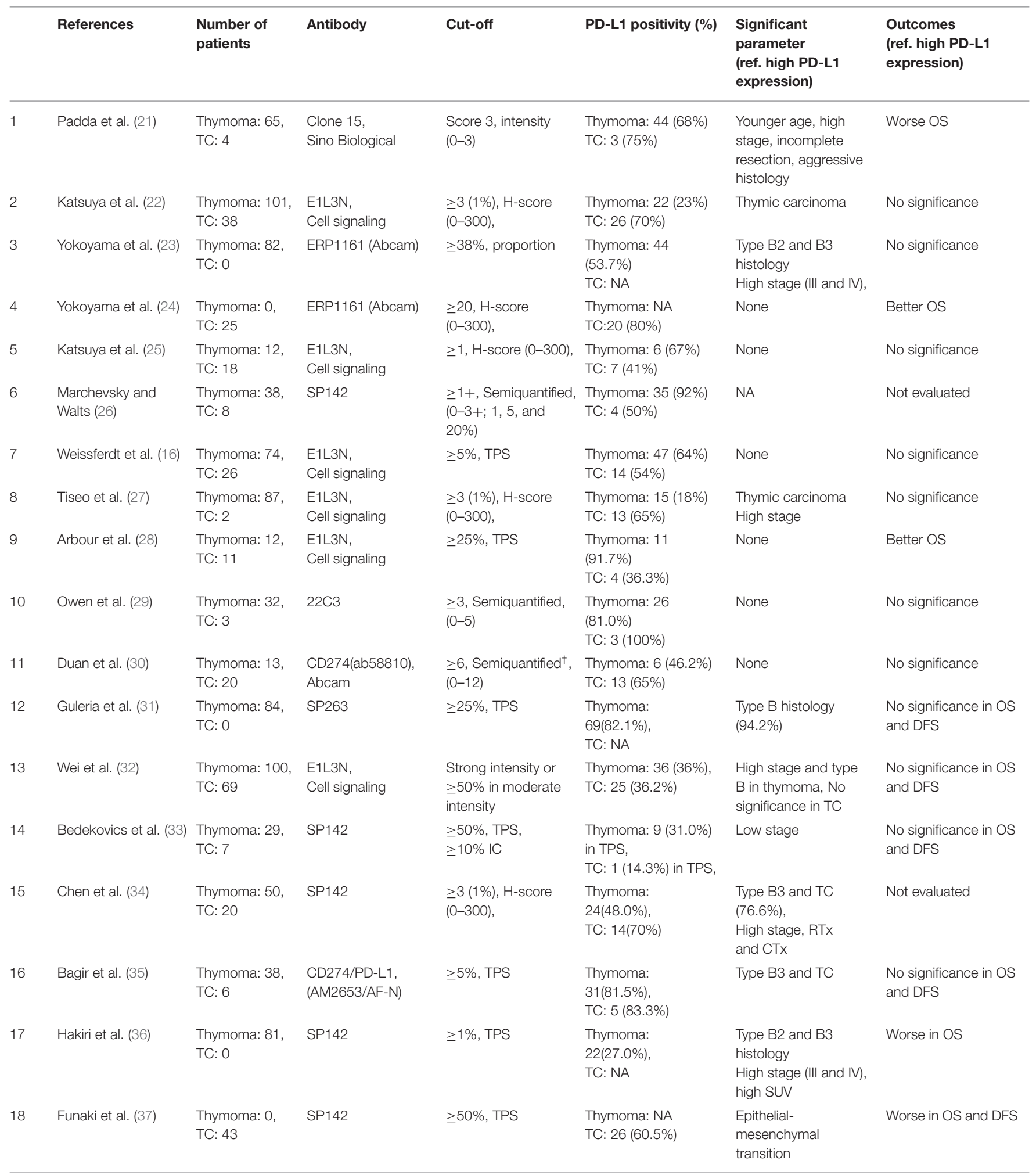

the percentage of positive tumor cells divided into five groups (5, 25, 50, and 70\%; 0-4) and multiplied into intensity (1-3), ranging from 0 to 12. The stage recorded according to Masaoka-Koga stage.

TC, thymic carcinoma; TPS, tumor proportion score; ref, reference parameter; OS, overall survival; DFS, disease-free survival; RTX, radiation therapy; CTX, chemotherapy; SUV, standard uptake value; NA, not available; IC, positive immune cells; ref, references. 
Interestingly, SP263 IHC was deemed to be superior due to its strong staining intensity and higher sensitivity compared to E1L3N in NSCLC (45). We chose SP263 for the following reasons: first, we were unable to purchase the $22 \mathrm{C} 3$ antibody for research use because, at the time of our study, 22C3 was permitted only for use in companion diagnosis support by a global drug company in Korea; second, the positive rate for SP142 was very low in NSCLC; third, we considered it useful to choose a clinically validated and druggable antibody.

Our study demonstrated the highest PD-L1 immunopositivity in thymomas (95.5\%, more than $1 \%$ cut-off) of all previous studies $(16,21-37)$. Thymomas are known to be rare epithelial tumors that occur more frequently in Asian patients, exhibiting higher staging and more frequent type B3 histology (46). Our study homogenously consisted of Korean patients and many cases of type B3 were included (36.5\%).

A higher number of $\mathrm{CD}^{+}$TILs has been associated with better OS in melanoma, NSCLC, colorectal, breast, and ovarian cancers (1-3). Duan et al. (30) revealed that CD8 $8^{\text {high }}$ TILs were associated with better OS in advanced thymic carcinoma; however, our study revealed no survival benefit in both OS ( $p$ $=0.351$, log-rank test) and DFS ( $p=0.913$, log-rank test). In addition, none of the CD8/PD-L1 combination groups showed any survival benefit in OS ( $p=0.509, \log$-rank) and DFS ( $p=$ 0.562, log-rank) in our study. Thus, the microenvironment of TETs may determine more than just CD8 activity; accordingly, more complex associations of immune cells could be considered.

Intra-tumoral and inter-tumoral heterogeneity of PD-L1 expression has been reported in NSCLC, with regard to the sampling issue (whole tumor section vs. biopsy or TMA) and location (primary or metastasis) (47). Gniadek et al. (47) compared 4 TMA cores from 150 formalin-fixed paraffinembedded tissues of resected primary cancers and found, in many cases, substantial inconsistencies in the percentages of cells staining positive for PD-L1 among the different TMA cores. Our study also revealed inconsistencies, in many cases, among three TMA cores from the same sample, and we calculated the average TPS. Only one study has considered tumor heterogeneity in examining PD-L1 in TETs (29).

Our immunogenomic analysis by unsupervised clustering analysis revealed that the immune profiles of thymomas and TC were significantly different and that PD-L1 mRNA expression was positively correlated with $\mathrm{PD}-\mathrm{L} 1$ protein expression (Spearman correlation analysis, $r=0.826, p<0.001$ ). In addition, the median PD-L1 mRNA level was higher in type $\mathrm{B} 3$ and TC than in the other thymomas, supporting the result that PD-L1 ${ }^{\text {high }}$ expression by IHC correlated with type B3 in thymoma. Chen et al. (32) performed immunogenomic analysis of PD-L1 expression level in TETs using the TCGA database; their results were similar to ours-PD-L1 protein expression was correlated with PD-L1 mRNA expression level and PD-L1 mRNA expression level differed $(p=0.0419)$ between TC (median 9.39) and thymomas (median 5.68), suggesting that high PD-L1 expression was considerably correlated with TET malignancy.

To the best of our knowledge, this is the largest study published to date that focuses on a homogenous racial population. We believe that this study will provide useful information for the application of therapeutic drugs. Nevertheless, our study has several limitations: first, the cohort contained patients that underwent surgical resection of an adequate specimen for TMA, excluding inoperable cases. Second, this study was performed using TMA rather than whole tumor sections; thus, the possibility of false negative or positive results remains, despite the fact that we attempted to overcome this problem by making TMAs in triplicate.

In conclusion, our study revealed that PD-L1 expression was frequent in TETs and associated with high Masaoka-Koga staging; moreover, WHO classification of type B3 was correlated with poor prognosis. In addition, PD-L1 expression is an independent prognostic factor in thymoma. Our results suggest the importance of appropriate patient selection in anti-PD-L1 therapy in TETs and the accurate pathologic diagnosis of TETs is essential to predict the patient's prognosis.

\section{DATA AVAILABILITY STATEMENT}

This manuscript contains previously unpublished data. The name of the repository and accession number(s) are not available.

\section{ETHICS STATEMENT}

This study was approved by the Ethics Committee of the Asan Medical Center (approval number: 2015- 965). The patients/participants provided their written informed consent to participate in this study.

\section{AUTHOR CONTRIBUTIONS}

JS and SJ: conception and design. JS, JK, and DK: development of the methodology. C-MC and HK: data acquisition. JS and DK: data analysis. JS, DK, and SJ: writing, review, and/or revision of manuscript. All contributors met the criteria for authorship and approved the final manuscript.

\section{FUNDING}

This study was supported by a grant (2015-664) from the Asan Institute for Life Science, Asan Medical Center, Seoul, Korea.

\section{ACKNOWLEDGMENTS}

The bio-specimens and data used in this study were provided by Asan Bio-Resource Center of the Korea Biobank Network [Seoul, South Korea, 2015-16 (106)]. The authors thank Dr. Joon Seo Lim from the Scientific Publications Team at Asan Medical Center for his editorial assistance in preparing this manuscript.

\section{SUPPLEMENTARY MATERIAL}

The Supplementary Material for this article can be found online at: https://www.frontiersin.org/articles/10.3389/fonc. 2019.01055/full\#supplementary-material 


\section{REFERENCES}

1. Alexe G, Dalgin GS, Scanfeld D, Tamayo P, Mesirov JP, DeLisi C, et al. High expression of lymphocyte-associated genes in node-negative HER2+ breast cancers correlates with lower recurrence rates. Cancer Res. (2007) 67:10669-76. doi: 10.1158/0008-5472.CAN-07-0539

2. Dahlin AM, Henriksson ML, Van Guelpen B, Stenling R, Oberg A, Rutegard J, et al. Colorectal cancer prognosis depends on T-cell infiltration and molecular characteristics of the tumor. Mod Pathol. (2011) 24:67182. doi: $10.1038 /$ modpathol.2010.234

3. Hillen F, Baeten CI, van de Winkel A, Creytens D, van der Schaft DW, Winnepenninckx V, et al. Leukocyte infiltration and tumor cell plasticity are parameters of aggressiveness in primary cutaneous melanoma. Cancer Immunol Immunother. (2008) 57:97-106. doi: 10.1007/s00262-007-0353-9

4. Freeman GJ, Long AJ, Iwai Y, Bourque K, Chernova T, Nishimura H, et al. Engagement of the PD-1 immunoinhibitory receptor by a novel B7 family member leads to negative regulation of lymphocyte activation. J Exp Med. (2000) 192:1027-34. doi: 10.1084/jem.192.7.1027

5. Motzer RJ, Escudier B, McDermott DF, George S, Hammers HJ, Srinivas S, et al. Nivolumab versus everolimus in advanced renal-cell carcinoma. $N$ Engl J Med. (2015) 373:1803-13. doi: 10.1056/NEJMoa1510665

6. Ferris RL, Blumenschein G Jr, Fayette J, Guigay J, Colevas AD, Licitra L, et al. Nivolumab for recurrent squamous-cell carcinoma of the head and neck. $N$ Engl J Med. (2016) 375:1856-67. doi: 10.1056/NEJMoa1602252

7. Reck M, Rodriguez-Abreu D, Robinson AG, Hui R, Csoszi T, Fulop A, et al. Pembrolizumab versus chemotherapy for PD-L1-positive non-smallcell lung cancer. N Engl J Med. (2016) 375:1823-33. doi: 10.1056/NEJMoa1 606774

8. Engels EA. Epidemiology of thymoma and associated malignancies. J Thorac Oncol. (2010) 5:S260-5. doi: 10.1097/JTO.0b013e3181f1f62d

9. Travis WD, Brambilla E, Burke AP, Marx A, Nicholson AG. WHO Classification of Tumors of the Lung, Pleura, Thymus and Heart. Lyon: International Agency for Research on Cancer (2015).

10. Giaccone G, Kim C, Thompson J, McGuire C, Kallakury B, Chahine JJ, et al. Pembrolizumab in patients with thymic carcinoma: a single-arm, single-centre, phase 2 study. Lancet Oncol. (2018) 19:347-55. doi: 10.1016/S1470-2045(18)30062-7

11. Kim KH, Cho J, Ku BM, Koh J, Sun JM, Lee SH, et al. The first-week proliferative response of peripheral blood PD-1(+)CD8(+) T cells predicts the response to anti-PD-1 therapy in solid tumors. Clin Cancer Res. (2019) 25:2144-54. doi: 10.1158/1078-0432.CCR-18-1449

12. Detterbeck FC, Nicholson AG, Kondo K, Van Schil P, Moran C. The Masaoka-Koga stage classification for thymic malignancies: clarification and definition of terms. J Thorac Oncol. (2011) 6:S1710-16. doi: 10.1097/JTO.0b013e31821e8cff

13. Planchard D, Yokoi T, McCleod MJ, Fischer JR, Kim YC, Ballas M, et al. A phase III study of durvalumab (MEDI4736) with or without tremelimumab for previously treated patients with advanced NSCLC: rationale and protocol design of the ARCTIC study. Clin Lung Cancer. (2016) 17:232-6 e1. doi: 10.1016/j.cllc.2016.03.003

14. Herbst RS, Baas P, Kim DW, Felip E, Perez-Gracia JL, Han JY, et al. Pembrolizumab versus docetaxel for previously treated, PD-L1-positive, advanced non-small-cell lung cancer (KEYNOTE010): a randomised controlled trial. Lancet. (2016) 387:154050. doi: 10.1016/S0140-6736(15)01281-7

15. Scheel AH, Dietel M, Heukamp LC, Johrens $K$, Kirchner T, Reu S, et al. Harmonized PD-L1 immunohistochemistry for pulmonary squamous-cell and adenocarcinomas. Mod Pathol. (2016) 29:1165-72. doi: 10.1038/modpathol.2016.117

16. Weissferdt A, Fujimoto J, Kalhor N, Rodriguez J, Bassett R, Wistuba II, et al. Expression of PD-1 and PD-L1 in thymic epithelial neoplasms. Mod Pathol. (2017) 30:826-33. doi: 10.1038/modpathol.2017.6

17. Wang K, Singh D, Zeng Z, Coleman SJ, Huang Y, Savich GL, et al. MapSplice: accurate mapping of RNA-seq reads for splice junction discovery. Nucleic Acids Res. (2010) 38:e178. doi: 10.1093/nar/gkq622

18. Gaujoux R, Seoighe C. A flexible R package for nonnegative matrix factorization. BMC Bioinformatics. (2010) 11:367. doi: 10.1186/1471-2105-11-367
19. Huang da W, Sherman BT, Zheng X, Yang J, Imamichi T, Stephens R, et al. Extracting biological meaning from large gene lists with DAVID. Curr Protoc Bioinformatics. (2009). 27:13.11.1-13. doi: 10.1002/0471250953. bi1311s27

20. Newman AM, Liu CL, Green MR, Gentles AJ, Feng W, Xu Y, et al. Robust enumeration of cell subsets from tissue expression profiles. Nat Methods. (2015) 12:453-7. doi: 10.1038/nmeth.3337

21. Padda SK, Riess JW, Schwartz EJ, Tian L, Kohrt HE, Neal JW, et al. Diffuse high intensity PD-L1 staining in thymic epithelial tumors. J Thorac Oncol. (2015) 10:500-8. doi: 10.1097/JTO.0000000000000429

22. Katsuya Y, Fujita Y, Horinouchi H, Ohe Y, Watanabe S, Tsuta K. Immunohistochemical status of PD-L1 in thymoma and thymic carcinoma. Lung Cancer. (2015) 88:154-9. doi: 10.1016/j.lungcan.2015.03.003

23. Yokoyama S, Miyoshi H, Nishi T, Hashiguchi T, Mitsuoka M, Takamori $\mathrm{S}$, et al. Clinicopathologic and prognostic implications of programmed death ligand 1 expression in thymoma. Ann Thorac Surg. (2016) 101:13619. doi: 10.1016/j.athoracsur.2015.10.044

24. Yokoyama S, Miyoshi H, Nakashima K, Shimono J, Hashiguchi T, Mitsuoka $\mathrm{M}$, et al. Prognostic value of programmed death ligand 1 and programmed death 1 expression in thymic carcinoma. Clin Cancer Res. (2016) 22:472734. doi: 10.1158/1078-0432.CCR-16-0434

25. Katsuya Y, Horinouchi H, Asao T, Kitahara S, Goto Y, Kanda S, et al. Expression of programmed death 1 (PD-1) and its ligand (PDL1) in thymic epithelial tumors: impact on treatment efficacy and alteration in expression after chemotherapy. Lung Cancer. (2016) 99:410. doi: 10.1016/j.lungcan.2016.05.007

26. Marchevsky AM, Walts AE. PD-L1, PD-1, CD4, and CD8 expression in neoplastic and nonneoplastic thymus. Hum Pathol. (2017) 60:1623. doi: 10.1016/j.humpath.2016.09.023

27. Tiseo M, Damato A, Longo L, Barbieri F, Bertolini F, Stefani A, et al. Analysis of a panel of druggable gene mutations and of ALK and PD-L1 expression in a series of thymic epithelial tumors (TETs). Lung Cancer. (2017) 104:2430. doi: 10.1016/j.lungcan.2016.12.005

28. Arbour KC, Naidoo J, Steele KE, Ni A, Moreira AL, Rekhtman $\mathrm{N}$, et al. Expression of PD-L1 and other immunotherapeutic targets in thymic epithelial tumors. PLoS ONE. (2017) 12:e0182665. doi: 10.1371/journal.pone.0182665

29. Owen D, Chu B, Lehman AM, Annamalai L, Yearley JH, Shilo K, et al. Expression patterns, prognostic value, and intratumoral heterogeneity of PDL1 and PD-1 in thymoma and thymic carcinoma. J Thorac Oncol. (2018) 13:1204-12. doi: 10.1016/j.jtho.2018.04.013

30. Duan J, Liu X, Chen H, Sun Y, Liu Y, Bai H, et al. Impact of PD-L1, transforming growth factor-beta expression and tumor-infiltrating $\mathrm{CD} 8(+) \mathrm{T}$ cells on clinical outcome of patients with advanced thymic epithelial tumors. Thorac Cancer. (2018) 9:1341-53. doi: 10.1111/1759-7714.12826

31. Guleria P, Husain N, Shukla S, Kumar S, Parshad R, Jain D. PD-L1 immunoexpression assay in thymomas: study of 84 cases and review of literature. Ann Diagn Pathol. (2018) 34:135-41. doi: 10.1016/j.anndiagpath.2018.03.012

32. Wei YF, Chu CY, Chang CC, Lin SH, Su WC, Tseng YL, et al. Different pattern of PD-L1, IDO, and FOXP3 Tregs expression with survival in thymoma and thymic carcinoma. Lung Cancer. (2018) 125:3542. doi: 10.1016/j.lungcan.2018.09.002

33. Bedekovics J, Beke L, Mokanszki A, Szilagyi S, Mehes G. Programmed death-ligand 1 (PD-L1) expression in thymic epithelial tumors. Appl Immunohistochem Mol Morphol. (2018). doi: 10.1097/PAI.0000000000000699. [Epub ahead of print].

34. Chen Y, Zhang Y, Chai X, Gao J, Chen G, Zhang W, et al. Correlation between the expression of PD-L1 and clinicopathological features in patients with thymic epithelial tumors. Biomed Res Int. (2018) 2018:5830547. doi: 10.1155/2018/5830547

35. Bagir EK, Acikalin A, Avci A, Gumurdulu D, Paydas S. PD-1 and PD-L1 expression in thymic epithelial tumours and non-neoplastic thymus. J Clin Pathol. (2018) 71:637-41. doi: 10.1136/jclinpath-2017-204788

36. Hakiri S, Fukui T, Mori S, Kawaguchi K, Nakamura S, Ozeki $\mathrm{N}$, et al. Clinicopathologic features of thymoma with the expression of programmed death ligand 1. Ann Thorac Surg. (2019) 107:418-24. doi: 10.1016/j.athoracsur.2018. 08.037 
37. Funaki S, Shintani Y, Fukui E, Yamamoto Y, Kanzaki R, Ose N, et al. The prognostic impact of programmed cell death 1 and its ligand and the correlation with epithelial-mesenchymal transition in thymic carcinoma. Cancer Med. (2019) 8:216-26. doi: 10.1002/cam4.1943

38. Garassino MC, Cho BC, Kim JH, Mazieres J, Vansteenkiste J, Lena H, et al. Durvalumab as third-line or later treatment for advanced non-small-cell lung cancer (ATLANTIC): an open-label, single-arm, phase 2 study. Lancet Oncol. (2018) 19:521-36. doi: 10.1016/S1470-2045(18)30144-X

39. Fehrenbacher L, Spira A, Ballinger M, Kowanetz M, Vansteenkiste J, Mazieres J, et al. Atezolizumab versus docetaxel for patients with previously treated non-small-cell lung cancer (POPLAR): a multicentre, open-label, phase 2 randomised controlled trial. Lancet. (2016) 387:183746. doi: 10.1016/S0140-6736(16)00587-0

40. Garon EB, Rizvi NA, Hui R, Leighl N, Balmanoukian AS, Eder JP, et al. Pembrolizumab for the treatment of non-small-cell lung cancer. N Engl J Med. (2015) 372:2018-28. doi: 10.1056/NEJMoa1501824

41. Rimm DL, Han G, Taube JM, Yi ES, Bridge JA, Flieder DB, et al. A prospective, multi-institutional, pathologist-based assessment of 4 immunohistochemistry assays for PD-L1 expression in non-small cell lung cancer. JAMA Oncol. (2017) 3:1051-8. doi: 10.1001/jamaoncol.2017.0013

42. Ratcliffe MJ, Sharpe A, Midha A, Barker C, Scott M, Scorer P, et al. Agreement between programmed cell death ligand-1 diagnostic assays across multiple protein expression cutoffs in non-small cell lung cancer. Clin Cancer Res. (2017) 23:3585-91. doi: 10.1158/1078-0432.CCR-16-2375

43. Hirsch FR, McElhinny A, Stanforth D, Ranger-Moore J, Jansson M, Kulangara $\mathrm{K}$, et al. PD-L1 immunohistochemistry assays for lung cancer: results from phase 1 of the blueprint PD-L1 IHC assay comparison project. J Thorac Oncol. (2017) 12:208-22. doi: 10.1016/j.jtho.2016.11.2228
44. Sakane T, Murase T, Okuda K, Takino H, Masaki A, Oda R, et al. A comparative study of PD-L1 immunohistochemical assays with four reliable antibodies in thymic carcinoma. Oncotarget. (2018) 9:69937009. doi: 10.18632 /oncotarget. 24075

45. Smith J, Robida MD, Acosta K, Vennapusa B, Mistry A, Martin G, et al. Quantitative and qualitative characterization of Two PD-L1 clones: SP263 and E1L3N. Diagn Pathol. (2016) 11:44. doi: 10.1186/s13000-016-0494-2

46. Weis CA, Yao X, Deng Y, Detterbeck FC, Marino M, Nicholson AG, et al. The impact of thymoma histotype on prognosis in a worldwide database. J Thorac Oncol. (2015) 10:367-72. doi: 10.1097/JTO.00000000000 00393

47. Gniadek TJ, Li QK, Tully E, Chatterjee S, Nimmagadda S, Gabrielson E. Heterogeneous expression of PD-L1 in pulmonary squamous cell carcinoma and adenocarcinoma: implications for assessment by small biopsy. Mod Pathol. (2017) 30:530-8. doi: 10.1038/modpathol.20 16.213

Conflict of Interest: The authors declare that the research was conducted in the absence of any commercial or financial relationships that could be construed as a potential conflict of interest.

Copyright (๑) 2019 Song, Kim, Kwon, Kim, Choi and Jang. This is an open-access article distributed under the terms of the Creative Commons Attribution License (CC $B Y)$. The use, distribution or reproduction in other forums is permitted, provided the original author(s) and the copyright owner(s) are credited and that the original publication in this journal is cited, in accordance with accepted academic practice. No use, distribution or reproduction is permitted which does not comply with these terms. 